\title{
Mechanical Properties of Copper/Bronze Laminates: Role of Interfaces
}

Xiaolong $\mathrm{Ma}^{\mathrm{a}}$, Chongxiang Huang ${ }^{\mathrm{b}}$, Jordan Moering ${ }^{\mathrm{a}}$, Mathis Ruppert ${ }^{\mathrm{c}}$, Heinz Werner Höppel ${ }^{\mathrm{c}}$, Mathias Göken ${ }^{\mathrm{c}}$, Jagdish Narayan ${ }^{\mathrm{a}}$, Yuntian $\mathrm{Zhu}^{\mathrm{a}, \mathrm{d} *}$

a Department of Materials Science and Engineering, North Carolina State University, Raleigh, NC 27695, USA

${ }^{\mathrm{b}}$ School of Aeronautics and Astronautics, Sichuan University, Chengdu 610065, China

${ }^{\mathrm{c}}$ Department of Materials Science and Engineering, Institute I: General Materials Properties, Friedrich-Alexander Universität Erlangen-Nürnberg, Martensstr. 5, 91058 Erlangen, Germany

${ }^{\mathrm{d}}$ School of Materials Science and Engineering, Nanjing University of Science and Technology, Nanjing 210094, China

*Corresponding author $\quad$ E-mail: chxhuang@scu.edu.cn ytzhu@ncsu.edu

Interfaces play a crucial role in mechanical behaviors of both laminated and gradient structured materials. In this work, copper/bronze laminates with varying interface spacing were fabricated by accumulative roll bonding and subsequent annealing to systematically study the interface effect on mechanical properties. Heterogeneities exist in chemical composition, grain size, hardness and texture across the interfaces. Simultaneous improvement of strength and ductility with decreasing interface spacing is found in tensile tests. Extra geometrically necessary dislocations (GNDs) are found to accumulate in the vicinity of interfaces, which is due to mechanical incompatibility across the interfaces. Importantly, an interface-affected zone spanning a few micrometers was found, which is not affected by interface spacing. These observations suggest the existence of an optimum spacing, which may produce the highest hardening capacity and ductility without sacrificing strength.

Keywords: Interface, Laminate structure, Geometrically necessary dislocation (GND), Interfaceaffected zone, Back stress hardening 


\section{Introduction}

Laminate and gradient structured metals have recently attracted extensive interests in the materials community for their potential in achieving outstanding mechanical properties [1-6]. Fang et al. and Wu et al. reported that gradient structures with nanocrystalline surface layers and coarse-grained interior produced a superior combination of strength and ductility [1,5,7]. Wu et al. reported that heterogeneous lamella-structured pure $\mathrm{Ti}$ possessed both the high strength of ultrafine grains and the decent ductility of the coarse grains [8]. Both laminate and gradient structures contain interfaces, across which there are differences in chemical compositions and/or microstructures, such as grain sizes and crystallographic orientations (texture) [9-11]. Interfaces were believed to significantly contribute to the observed high strain hardening and ductility in both laminate and gradient materials [3,12-15]. Kümmel et al. [16] attributed this to an additional grain refinement caused by an increasing number of interface, which, however, is not an intrinsic effect from interfaces. Some researchers proposed that gradient distribution of stress near the interface enhances working hardening in multi-layered and gradient structured metals [3,17-19]. $\mathrm{Wu}$ and $\mathrm{Zhu}$ found that strain gradient and the associated back-stress strengthening near the interfaces played a critical role in the high strength and high strain hardening rate [5,8,20,21].

Early literatures have linked microstructural heterogeneity with strain gradient evolution and subsequent generation of geometrically necessary dislocations (GNDs) during plastic deformation [22-25]. Applying this general theory to laminates, Ashby et al. developed a reciprocal relationship between the average GND density and interface spacing in an idealized laminate structure with a single crystal matrix and equally spaced rigid plate-like particles [22]. However, this theory was based on simple assumptions, which does not represent real complex materials very well. In fact, laminate components are mostly engineered from polycrystalline matrix and none of them are absolutely rigid [26,27]. Additionally, the details of GND density configuration and their dependence on interface spacing are not well described in the conventional theory and have been rarely investigated experimentally. These issues are critical to understanding the fundamental mechanisms and imperative to practical material design. For example, to what extent and distance does an interface exerts influence during deformation? Does the width of the interface-affected zone depend on the interface spacing/layer thickness? Very few systematic studies have been reported to explore these issues.

It has been a grand challenge to investigate the aforementioned issues through direct experimental observations. First, in gradient structures, the microstructural interfaces also act as elastic/plastic and necking/stable interfaces during tensile testing. Thus, rather than being 
stationary, those interfaces migrate dynamically across the samples during deformation due to the strength/ductility gradient, which makes it difficult to identify or track them experimentally $[1,5,7]$. Second, even for laminate structures with stationary interfaces, it is not trivial to fabricate samples with varying interface spacing and also with similar microstructure across the interface in terms of the grain size and texture. For example, the majority of laminate metallic structures fabricated by accumulative roll bonding (ARB) always have finer microstructures with increasing rolling cycles [28,29]. Furthermore, even atomic structure of interface might change with decreasing interface spacing [4,30]. To effectively probe the effect of interfaces on mechanical performance, identical or very similar interfaces and interfacial structures with varying interface spacing are needed. Third, it is technically difficult to determine the deformation characteristics, such as dislocation density and their evolutions, near the interface using conventional approaches such as transmission electron microscopy (TEM) because of the inhomogeneous nature of dislocation slips [31].

In the present study, copper and bronze $(\mathrm{Cu}-10 \mathrm{wt} \% \mathrm{Zn})$ laminates with varying interfacial spacing were fabricated using ARB processing and post-annealing. These samples have maintained almost the same level of microstructural difference across their interfaces. Using exsitu electron back-scattering diffraction (EBSD) technique, the deformation history of interface regions under tension were successfully recorded, which revealed how and to what extent do these interfaces affect GND activities [32-34]. Unloading-reloading tension tests were performed to further confirm the role of the interfaces in back stress evolution.

\section{Experimental Methods}

Commercial pure copper (ASM-C11000) and bronze (ASM-C22000) were selected for this work. The chemical compositions and general mechanical properties of these raw materials are listed in Table 1 [35,36]. The advantage of these two materials is their similar elastic constants so that we don't have to consider the effect of elastic mismatch. 1mm-thick raw copper and bronze sheets were ARB-processed with 2, 3 and 5 cycles to achieve 4, 8 and 32 layers, respectively. Prior to each ARB cycle, the sample surfaces were cleaned by acetone and then wire brushed in order to remove oxide layer and to ensure a well-defined surface roughness and sufficient bonding strength. Subsequently, the two treated surfaces were stacked with an alternate sequence of copper and bronze, and roll-bonded at room temperature using a four high rolling mill (BW 200, CarlWezel, Mühlacker, Germany) at a nominal thickness reduction of $50 \%$ per cycle. The bonded sheets were air cooled and halved before performing the next cycle. The edge regions where sheets tend to tear from each other were cut away and the central part with good 
initial bonding strength was used for following processing. Details of ARB processing can be found in early works [26,37]. The as-ARB processed samples were annealed together at $250^{\circ} \mathrm{C}$ for $2 \mathrm{hrs}$ in a vacuum tube furnace under argon atmosphere and thereafter labeled as N2, N3 and $\mathrm{N} 5$, respectively.

Samples for Ion Channeling Contrast Microscopy (ICCM), micro-hardness testing and EBSD observation were first cut from the annealed samples and then mechanically polished to achieve a mirror-like surface. Electrochemical polishing was then performed for $<30$ s to remove the strained top-surface layer that may affect following tests. The electrolyte consisted of a phosphoric acid (concentration of $85 \%$ ), ethanol and deionized water with a volume ratio of 1:1:2. ICCM and EBSD were conducted under an FEI Quanta 3D FEG dual-beam instrument. Texture analysis was based on EBSD maps with a view area of $30 \times 100 \mu \mathrm{m}^{2}$ to capture the global characteristic. For local misorientation mapping, each EBSD scan was performed under $30 \mathrm{kV}$ and $16 n$ A electron beam and with a bin size of $2 \times 2$ to achieve a decent angular resolution [38,39]. Scan step size was set at $100 \mathrm{~nm}$ to ensure appropriate spatial resolution.

TEM foils were prepared by mechanically polishing specimen to a thickness of $\sim 30 \mu \mathrm{m}$, followed by ion milling to perforation. The milling process was performed at $-50^{\circ} \mathrm{C}$ to avoid potential grain growth. TEM observation was performed in a JEM-2010F microscope operating at $200 \mathrm{kV}$ at room temperature. Dog-bone shaped tensile samples with a gauge dimension of $10 \times 2 \times 1 \mathrm{~mm}^{3}$ were machined from the annealed sheets and tested under uniaxial tension on a Shimadzu AGS machine. Both normal and unloading-reloading tension tests were carried out at room temperature at a strain rate of $9 \times 10^{-4} \mathrm{~s}^{-1}$ and each test was repeated for at least 3 samples to ensure data reproducibility. Ex-situ EBSD mapping in the interfacial region was carried out on the same specimen at three strain levels: $0 \%, 3 \%$ and uniform elongation strain. The interfacial region of interest was carefully marked by a milling feature.

\section{Results}

\subsection{Microstructures}

Figures 1a-c are the optical microscopy images of all sample, which show clearly welldefined laminate structure with uniform layer thickness and varying interface spacing. The red color indicates the copper layers. The layer thickness for N2, N3 and N5 samples are 250, 125 and $31 \mu \mathrm{m}$, respectively. ICCM micrographs (Figures 1d-f) reveal similar microstructures in all samples subjected to different ARB cycles. Coarse copper grains with considerable annealing twins are observed in all N2, N3 and N5 samples. The annealing twins were formed by 
recrystallization during annealing, which is further confirmed by texture analysis later. In contrast, the bronze layer maintained largely the rolling structure in all samples due to its higher thermal stability. Figure 1 shows slightly larger grain size in the bronze layer of the N2 sample than in the N3 and N5 samples. This is probably resulted from the relatively low rolling strain in the N2 sample. However, as shown later, the differences in their hardness and texture are not significant. Small quantities of nanocrystalline bronze grains were locally dispersed in the vicinity of the interfaces, which is observed in all samples under ICCM.

\subsection{Heterogeneity across interfaces}

A representative copper/bronze interface in the N5 sample is shown in Figure 2a, which reveals a transition from coarse-grained copper to nanostructured bronze across the interface. Clearly, the recrystallized coarse-grained $\mathrm{Cu}$ grains are much larger and exhibit less dislocation contrast than the bronze layer. The latter still exhibit a deformed microstructure. Figure $2 b$ shows more microstructural details in the bronze layer, which reveals elongated grains along the rolling direction as well as dislocation cells and areas with high dislocation density. The statistical distributions of (transverse) grain sizes in the copper and bronze layers are shown in Figure 2c and $2 \mathrm{~d}$, respectively. As shown, the bronze layer has an average feature size of $\sim 100 \mathrm{~nm}$, while the copper layer has an average grain size of $\sim 5 \mu \mathrm{m}$. Such grain size and composition difference are expected to produce a significant mechanical incompatibility across the interface.

The microstructural and compositional difference across the interface led to sharp difference in hardness. As shown in Figure 3a, the nanostructured bronze layer has a hardness of $\sim 1500 \mathrm{MPa}$, which is more than twice that in microcrystalline copper layer ( 700MPa). It is noted that the micro-hardness of both copper and bronze layers are very close in all samples, given the measurement errors, despite varying interface spacing. Crystallographic orientation (texture) was also found to differ remarkably across the interfaces. As shown in Figure 3b, copper exhibits a strong cube texture component $\{001\}<100>$, which is resulted from both recrystallization and grain growth [40]. In contrast, bronze shows $\{110\}<112>$ texture with slight variation $[40,41]$, which is consistent with previous reports of brass-type rolling texture in FCC alloys with low stacking-fault energy [42]. Post-annealing after ARB did not change the rolling texture of the bronze layer much, which is consistent with the TEM observation of rolling microstructure in Figure 2. Note that the present pole figures are scanned from the N3 sample, but N2 and N5 exhibit similar textures in the copper and bronze layers.

The above observations indicate that the ARB processing and appropriate annealing produced interfaces with varying spacing but similar microstructure, micro-hardness and texture. 
This allows us to study the interface effect on the mechanical properties without complications from other structural factors.

\subsection{Uniaxial tensile tests}

Figure 4a shows the tensile stress-strain curves for N2, N3 and N5 samples. Inset is a photograph of a sample. As shown, both the strength and uniform tensile elongation (ductility) increased with decreasing interface spacing. Interestingly, the yield strength did not increase as much as the ultimate strength, indicating that decreasing the interface spacing is more effective in enhancing the strain-hardening rate than yield strength. Figure $4 \mathrm{~b}$ summarizes the variation of ultimate strength and ductility, which confirms their reproducibility. It's worth noting that some earlier ARB studies also reported similar simultaneous improvements in strength and ductility with increasing rolling cycles, but most of these studies attributed this phenomenon to microstructure change instead of the interface spacing [29,43,44].

\subsection{Ex-situ EBSD mapping and GND characterization}

Figure 5 shows EBSD inverse pole figure mappings of the copper layers along the transverse direction, at zero strain, 3\% tensile strain and uniform elongation strain for each sample. Arrows indicate interfaces. Generally, the indexing rate is more than $97 \%$ even for copper grains near interfaces, making following interfacial analysis reliable. For the N5 sample, the whole copper layer is captured because it is thin. For each sample, the local crystal orientation in a region near an interface was measured at the above selected tensile strains to study the GND evolution. In this study, we used the kernel average misorientation (KAM) method to determine the local misorientation from the EBSD orientation data [34]. First, we defined the limit of the general grain boundary misorientation as $3^{\circ}$. Any misorientation greater than this value was excluded in local misorientation calculation since it is caused by a grain boundary, not by GND accumulation. The local misorientation of every single point $\left(100 \times 100 \mathrm{~nm}^{2}\right)$ was then determined by the 24 surrounding points:

$$
\theta_{0}=\sum_{i=1}^{24} \theta_{i} \cdot I_{\left(\theta_{i<\alpha}\right)} / \sum_{i=1}^{24} I_{\left(\theta_{i<\alpha}\right)}
$$

where $\theta_{0}$ represents the resulted local misorientation for the corresponding point and $\theta_{i}$ is the misorientation between this point and its neighbor point $i . i$ is an indicator function and $\alpha$ is the predefined grain boundary misorientation threshold $\left(3^{\circ}\right.$ here). To extrapolate the GND density information, we use a simple method from the strain gradient theory by Gao and Kubin [25,45]: 


$$
\rho^{\mathrm{GND}}=\frac{2 \theta}{u b}
$$

where $\rho^{\mathrm{GND}}$ is the GND density at points of interest, $\theta$ represents the local misorientation, $b$ is the Burger's vector $(0.255 \mathrm{~nm}$ for copper) and $u$ is the unit length $(100 \mathrm{~nm})$ of the point. The resulted GND density maps are shown in Figure 6 for all samples under corresponding tensile strains. Clearly, the overall level of GND density is elevated with increasing tensile strain. This is expected from the deformation of polycrystalline materials, which is inhomogeneous [22,31,32]. It is also noted that the GND density is not uniform across the whole mapping region, which is not considered in the conventional theory [22,24]. Figure 7 shows the histogram distribution of GND density for each map. The GND distributions in the three samples are very similar at each tensile strain. Here, we need to mention the measurement error in the study. Previous researches on EBSD technique indicated that the measurement error might dominate when the misorientation to measure is very small and the relative error decreases when increasing real misorientation $[39,46]$. Taking the extreme case by assuming that the misorientation under zero strain is caused by measurement error, the resulted upper limit of measurement error of GND density is less than $1.73 \times 10^{14} \mathrm{~m}^{-2}$, which is reasonable compared to an early report [47].

Figure 7 also shows that the variation of GND density increases with tensile strain. This is definitely a true deformation phenomenon, rather than measurement error, because the latter has an inverse trend [46]. Since the GND density is related to the strain gradient [22,25], these results indicate that the strain gradient is not uniform and this becomes more severe with increasing plastic strain. One source for the non-uniform strain gradient and GND density is the randomly distributed polycrystalline grain boundaries. They serve as barriers to dislocation motion and therefore locally generate GNDs [32,34]. The GND density is also affected by the crystallographic orientation, which varies from grain to grain. Another important source would be the macroscopic interfaces, which is the central interest in this study. To extract the effect of interfaces, the mapped regions in Figure 5 were sliced parallel to the interface and the average GND density in each slice was randomly sampled [48] to minimize the interference from grain boundaries, crystallographic orientation and other irrelevant factors. The resulted GND densities versus their equivalent distance from interfaces are shown in Figure 8, which reveals the development of a gradient in GND density near the interface. In other words, there is an interface-affected zone where the GNDs were accumulated during the tensile deformation. This zone spans only a few micrometers, and is observed in all three samples and becomes more pronounced with increasing applied tensile strain. It is also noted that the GND density in the 
layer interior becomes rather lower and uniform across all samples, i.e. the interface effect declined quickly with increasing distance from the interface.

\section{Discussions}

\subsection{Dislocation pile-up model for the GND density close to interfaces}

The heterogeneity in grain size, strength, stacking fault energy and texture between the copper and bronze layers makes them mechanically incompatible during deformation. However, the two different layers are forced to deform together, which generates strain gradient near the interface to fit the different strains across the interface. The strain gradient needs to be accommodated by GND, in the form of dislocation pile-up near the interface [49-51]. GND distributions were derived based on the conventional pile-up model [50], where the GND density $\rho^{\mathrm{GND}}(x)$ is inversely proportional to $k / \sqrt{x(a-x)}$. Here, $x$ is the distance from the interface, $k$ and $a$ are constants [50]. Defining the averaged GNDs arose from the grain boundary and orientation effects as $\rho_{0}^{\mathrm{GND}}$, the fitting function can be modified as

$$
\rho^{\mathrm{GND}}(x)=\frac{k}{\sqrt{x(a-x)}}+\rho_{0}^{\mathrm{GND}}
$$

Data sets from the uniform elongation strain level are used to fit the model because they are least affected by measurement noise. The fitting results (dashed green lines) of GND density are superimposed on the measured data in Figure 8, which demonstrate that the dislocation pile-up model can well describe the GND accumulation at interfaces in laminate structures. The fitting results also reveal that the $\rho_{0}^{\mathrm{GND}}$ values are very close for three samples with different interface spacing: $\rho_{0}^{\mathrm{GND}}=5.1,4.8$ and $4.9 \times 10^{14} \mathrm{~m}^{-2}$ in $\mathrm{N} 2, \mathrm{~N} 3$ and $\mathrm{N} 5$ samples, respectively. Figure 8 also shows that GND density close to interface is $\sim 10 \times 10^{14} \mathrm{~m}^{-2}$, indicating that interfaces doubled GND density locally.

Consistent with fitted $\rho_{0}^{\mathrm{GND}}$ in Figure 8, Figure 9 shows that the microhardness values in the copper and bronze layers after tensile testing to uniform elongation are almost the same in three samples. This indicates that the hardening capacities of the layer interior are approximately the same regardless of different interface density in samples. Therefore, the improved mechanical properties in Figure 4 are largely caused by the interface effect. 


\subsection{Role of interface in deformation of nanostructured bronze}

The average transverse grain size in the bronze layers is about $100 \mathrm{~nm}$, which makes it difficult to characterize the deformation history by the current EBSD technique due to its resolution limit. But the extra accumulation of GNDs is still expected to occur in the bronze side as well. Although the hardening in the bronze layer interior during tension is not as high as in the $\mathrm{Cu}$ layer (see Figure 9), extra hardening by GND accumulation could be generated in the nanostructured layer close to interfaces, which has been observed in gradient structures $[5,14]$.

In addition, interfaces are also expected to facilitate other deformation mechanisms in the nanostructured bronze, such as deformation twinning [52], to promote strain hardening and ductility. Such mechanisms could be activated in grains near the interface for the following reasons. First, the aforementioned dislocation pile-up will produce a shear stress field near the interface and this stress field is expected higher than that from ordinary pile-ups at conventional grain boundaries because the plastic incompatibility across such interface is higher $[49,50]$. Second, bi-metal interfaces could act as dislocation sources and sinks to facilitate plastic deformation [30]. Figure 10a shows a TEM micrograph of the copper/bronze interface after tensile deformation. Figure $10 \mathrm{~b}$ is the corresponding high-resolution micrograph. On the right side of the interface is a large copper grain with an annealing twin and the left is a bronze grain with only $30 \mathrm{~nm}$ grain size. A deformation twin in the bronze grain is probably nucleated at the interface by the transmission of the Shockley partial from the annealing $\mathrm{Cu}$ twin $[30,53]$.

\subsection{Effect of interface spacing on back stress hardening}

Dislocation pile-up will produce back stress, which is a long-range stress field that prohibits further dislocation emission from the dislocation source [50,54]. In other words, higher plastic flow stress is needed to overcome this field to sustain further deformation. This mechanism is highlighted in a recent work on Ti lamella microstructures [8]. The macroscopic interfaces here are expected to have similar effect. We calculated the back stress from unloadingreloading test curves at different tensile strains (see Figure 11a) using an equation recently proposed by Yang et al. [21]. As shown in Figure 11b, the resulted back stress is higher in samples with smaller interface spacing (higher interface density). This can be rationalized with the help of Figure 8, which reveals that each interface produces an interface-affected zone by considerable GND pile-ups. Consequently, higher interface density amounts to more GND pileups in a certain sample volume, leading to a higher observed back stress at the present spacing scale. 
However, further enhancement of back stress hardening and ductility may be limited when the interface spacing is smaller than a critical value since the transition of deformation mechanisms may occur [55]. This hypothesis is supported by reports that nanolaminates usually exhibit very high strength but disappointing tensile ductility [56-58]. In other words, there should be an optimum interface spacing that generates the extra GND pile-ups across the whole layer and yields the highest back stress hardening and ductility while maintaining high strength. We propose that this optimum spacing is comparable to the observed width of interface-affected zone, i.e. a few micrometers, which is consistent with recent report of aluminum alloy laminate composites [16] but still needs further investigations.

It should be also noted that further reducing interface spacing via ARB method will probably give rise to the preferred crystallographic orientations (textures) at bi-metal interfaces $[2,4,59]$. Such local and stable texture affects deformation and mechanical properties in its own way. When each layer is much thicker than the grain size dimension, its influence is trivial and the general interface effect governs the case [60], like in this work. The effect of interfacial texture is expected to interact with the general interface effect, which needs to be further studied.

\section{Conclusion}

In summary, we have systematically studied the effect of the copper/bronze interface on the deformation behavior and mechanical properties of laminate structures. The main conclusions are:

(1) The copper/bronze laminates were produced by means of ARB/annealing with varying interface spacing but similar heterogeneity across the interfaces including chemical composition, grain size, micro-hardness and texture.

(2) Both ultimate strength and ductility in uniaxial tension are improved with decreasing interface spacing, which can be primarily attributed to the effect of interfaces since other variables are kept almost the same.

(3) An interface-affected zone during deformation was experimentally observed. It spans a few micrometers regardless of varying interface spacing. Within this zone, non-uniform strain gradient and GND accumulation were generated via dislocation pile-up. In contrast, hardening capacity in the layer interior is about the same across samples.

(4) Interfaces affect adjacent layers during deformation and promotes back stress hardening by producing more GND pile-ups. It's our hypothesis that there exists an optimum 
interface spacing, comparable to the width of interface-affected zone, for the highest ductility without sacrifice of strength.

\section{Acknowledgements}

This work is supported by the US Army Research Office (W911 NF-12-1-0009), the US National Science Foundation (DMT-1104667) as well as National Natural Science Foundation of China (No. 11172187). Y.T. Zhu also acknowledges the support of Jiangsu Key Laboratory of Advanced Micro \& Nano Materials and Technology, Nanjing University of Science and Technology. The authors acknowledge the use of the Analytical Instrumentation Facility (AIF) at North Carolina State University, which is supported by the State of North Carolina and the National Science Foundation. 


\section{References}

[1] T.H. Fang, W.L. Li, N.R. Tao, K. Lu, Revealing Extraordinary Intrinsic Tensile Plasticity in Gradient Nano-Grained Copper, Science. 331 (2011) 1587-1590. doi:10.1126/science.1200177.

[2] S. Zheng, I.J. Beyerlein, J.S. Carpenter, K. Kang, J. Wang, W. Han, N.A. Mara, Highstrength and thermally stable bulk nanolayered composites due to twin-induced interfaces, Nature Communications. 4 (2013) 1696. doi:10.1038/ncomms2651.

[3] D.K. Yang, P. Cizek, D. Fabijanic, J.T. Wang, P.D. Hodgson, Work hardening in ultrafine-grained titanium: Multilayering and grading, Acta Materialia 61 (2013) 2840-2852. doi:http://dx.doi.org/10.1016/j.actamat.2013.01.018.

[4] I.J. Beyerlein, J.R. Mayeur, S. Zheng, N.A. Mara, J. Wang, A. Misra, Emergence of stable interfaces under extreme plastic deformation, Proceedings of the National Academy of Sciences. 111 (2014) 4386-4390. doi:10.1073/pnas.1319436111.

[5] X. Wu, P. Jiang, L. Chen, F. Yuan, Y.T. Zhu, Extraordinary strain hardening by gradient structure, Proceedings of the National Academy of Sciences. 111 (2014) 7197-7201. doi:10.1073/pnas.1324069111.

[6] J. Lu, H.L. Chan, A.Y. Chen, H.N. Kou, Mechanics of High Strength and High Ductility Materials, Procedia Engineering 10 (2011) 2202-2207. doi:http://dx.doi.org/10.1016/j.proeng.2011.04.364.

[7] X.L. Wu, P. Jiang, L. Chen, J.F. Zhang, F.P. Yuan, Y.T. Zhu, Synergetic Strengthening by Gradient Structure, Mater. Res. Lett. (2014) 1-7. doi:10.1080/21663831.2014.935821.

[8] X. Wu, M. Yang, F. Yuan, G. Wu, Y. Wei, X. Huang, Y. Zhu, Heterogeneous lamella structure unites ultrafine-grain strength with coarse-grain ductility, Proceedings of the National Academy of Sciences. (2015) 201517193. doi:10.1073/pnas.1517193112.

[9] S.-B. Lee, J.E. LeDonne, S.C.V. Lim, I.J. Beyerlein, A.D. Rollett, The heterophase interface character distribution of physical vapor-deposited and accumulative roll-bonded $\mathrm{Cu}-\mathrm{Nb}$ multilayer composites, Acta Materialia. 60 (2012) 1747-1761. doi:10.1016/j.actamat.2011.12.007.

[10] X.C. Liu, H.W. Zhang, K. Lu, Formation of nano-laminated structure in nickel by means of surface mechanical grinding treatment, Acta Materialia. 96 (2015) 24-36.

doi:10.1016/j.actamat.2015.06.014.

[11] Y. Mishin, M. Asta, J. Li, Atomistic modeling of interfaces and their impact on microstructure and properties, Acta Materialia. 58 (2010) 1117-1151.

doi:10.1016/j.actamat.2009.10.049.

[12] S. Suresh, Graded Materials for Resistance to Contact Deformation and Damage, Science. 292 (2001) 2447-2451. doi:10.1126/science. 1059716.

[13] L. Jianjun, A. K. Soh, Enhanced ductility of surface nano-crystallized materials by modulating grain size gradient, Modelling and Simulation in Materials Science and Engineering. 20 (2012) 085002.

[14] J. Li, S. Chen, X. Wu, A.K. Soh, A physical model revealing strong strain hardening in nano-grained metals induced by grain size gradient structure, Materials Science and Engineering: A. 620 (2015) 16-21. doi:10.1016/j.msea.2014.09.117.

[15] K. Lu, Making strong nanomaterials ductile with gradients, Science. 345 (2014) 14551456. doi:10.1126/science.1255940. 
[16] F. Kümmel, M. Kreuz, T. Hausöl, H. Höppel, M. Göken, Microstructure and Mechanical Properties of Accumulative Roll-Bonded AA1050A/AA5005 Laminated Metal Composites, Metals. 6 (2016) 56. doi:10.3390/met6030056.

[17] H.F. Tan, B. Zhang, X.M. Luo, X.D. Sun, G.P. Zhang, Strain rate dependent tensile plasticity of ultrafine-grained $\mathrm{Cu} / \mathrm{Ni}$ laminated composites, Materials Science and Engineering: A. 609 (2014) 318-322. doi:10.1016/j.msea.2014.04.111.

[18] S.S. Chakravarthy, W.A. Curtin, Stress-gradient plasticity, Proceedings of the National Academy of Sciences. 108 (2011) 15716-15720. doi:10.1073/pnas.1107035108.

[19] Z. Zeng, X. Li, D. Xu, L. Lu, H. Gao, T. Zhu, Gradient plasticity in gradient nanograined metals, Extreme Mechanics Letters. (2015). doi:10.1016/j.eml.2015.12.005.

[20] X.L. Ma, C.X. Huang, W.Z. Xu, H. Zhou, X.L. Wu, Y.T. Zhu, Strain hardening and ductility in a coarse-grain/nanostructure laminate material, Scripta Materialia. 103 (2015) 57-60. doi:10.1016/j.scriptamat.2015.03.006.

[21] M. Yang, Y. Pan, F. Yuan, Y. Zhu, X. Wu, Back stress strengthening and strain hardening in gradient structure, Materials Research Letters. (2016) 1-7.

doi:10.1080/21663831.2016.1153004.

[22] M.F. Ashby, The deformation of plastically non-homogeneous materials, Philosophical Magazine. 21 (1970) 399-424. doi:10.1080/14786437008238426.

[23] N.A. Fleck, G.M. Muller, M.F. Ashby, J.W. Hutchinson, Strain gradient plasticity: Theory and experiment, Acta Metallurgica et Materialia. 42 (1994) 475-487. doi:10.1016/09567151(94)90502-9.

[24] W.D. Nix, H. Gao, Indentation size effects in crystalline materials: A law for strain gradient plasticity, Journal of the Mechanics and Physics of Solids. 46 (1998) 411-425. doi:10.1016/S0022-5096(97)00086-0.

[25] H. Gao, Mechanism-based strain gradient plasticity I. Theory, Journal of the Mechanics and Physics of Solids. 47 (1999) 1239-1263. doi:10.1016/S0022-5096(98)00103-3.

[26] H.P. Ng, T. Przybilla, C. Schmidt, R. Lapovok, D. Orlov, H.-W. Höppel, M. Göken, Asymmetric accumulative roll bonding of aluminium-titanium composite sheets, Materials Science and Engineering: A. 576 (2013) 306-315. doi:10.1016/j.msea.2013.04.027.

[27] K. Tanaka, K. Shibata, K. Kurumatani, S. Ikeuchi, S. Kikuchi, R. Kondo, H.T. Takeshita, Formation mechanism of micro/nano-structures through competitive reactions in $\mathrm{Mg} / \mathrm{Cu}$ superlaminate composites during initial hydrogenation, Journal of Alloys and Compounds. 645 (2015) S72-S75. doi:10.1016/j.jallcom.2015.01.196.

[28] M. Eizadjou, A. Kazemitalachi, H. Daneshmanesh, H. Shakurshahabi, K. Janghorban, Investigation of structure and mechanical properties of multi-layered $\mathrm{Al} / \mathrm{Cu}$ composite produced by accumulative roll bonding (ARB) process, Composites Science and Technology. 68 (2008) 2003-2009. doi:10.1016/j.compscitech.2008.02.029.

[29] M. Ruppert, C. Schunk, D. Hausmann, H.W. Höppel, M. Göken, Global and local strain rate sensitivity of bimodal Al-laminates produced by accumulative roll bonding, Acta Materialia. 103 (2016) 643-650. doi:10.1016/j.actamat.2015.11.009.

[30] N.A. Mara, I.J. Beyerlein, Review: effect of bimetal interface structure on the mechanical behavior of $\mathrm{Cu}-\mathrm{Nb}$ fcc-bcc nanolayered composites, Journal of Materials Science. 49 (2014) 6497-6516. doi:10.1007/s10853-014-8342-9. 
[31] B. Bay, N. Hansen, D.A. Hughes, D. Kuhlmann-Wilsdorf, Overview no. 96 evolution of f.c.c. deformation structures in polyslip, Acta Metallurgica et Materialia. 40 (1992) 205-219. doi:10.1016/0956-7151(92)90296-Q.

[32] J. Jiang, T.B. Britton, A.J. Wilkinson, Evolution of dislocation density distributions in copper during tensile deformation, Acta Materialia. 61 (2013) 7227-7239. doi:10.1016/j.actamat.2013.08.027.

[33] P.D. Littlewood, A.J. Wilkinson, Geometrically necessary dislocation density distributions in cyclically deformed Ti-6Al-4V, Acta Materialia. 60 (2012) 5516-5525. doi:10.1016/j.actamat.2012.07.003.

[34] M. Calcagnotto, D. Ponge, E. Demir, D. Raabe, Orientation gradients and geometrically necessary dislocations in ultrafine grained dual-phase steels studied by 2D and 3D EBSD, Materials Science and Engineering: A. 527 (2010) 2738-2746. doi:10.1016/j.msea.2010.01.004.

[35] P.C.J. Gallaghe, Influence of alloying, temperature, and related effects on stacking fault energy, Metallurgical Transactions. 1 (1970) 2429.

[36] ASM International, J.R. Davis, ASM International, eds., Properties and selection: nonferrous alloys and special-purpose materials, [10. ed.], 6. print, ASM International, Materials Park, Ohio, 2000.

[37] C.W. Schmidt, M. Ruppert, H.W. Höppel, F. Nachtrab, A. Dietrich, R. Hanke, M. Göken, Design of Graded Materials by Particle Reinforcement During Accumulative Roll Bonding: Design of Graded Materials by Particle Reinforcement During ARB, Advanced Engineering Materials. 14 (2012) 1009-1017. doi:10.1002/adem.201200046.

[38] J. Jiang, T.B. Britton, A.J. Wilkinson, Measurement of geometrically necessary dislocation density with high resolution electron backscatter diffraction: Effects of detector binning and step size, Ultramicroscopy. 125 (2013) 1-9. doi:10.1016/j.ultramic.2012.11.003.

[39] I. Brough, P.S. Bate, F.J. Humphreys, Optimising the angular resolution of EBSD, Materials Science and Technology. 22 (2006) 1279-1286. doi:10.1179/174328406X130902.

[40] T. Leffers, R.K. Ray, The brass-type texture and its deviation from the copper-type texture, Progress in Materials Science. 54 (2009) 351-396. doi:10.1016/j.pmatsci.2008.09.002.

[41] J. Hirsch, K. Lücke, Overview no. 76, Acta Metallurgica. 36 (1988) 2863-2882. doi:10.1016/0001-6160(88)90172-1.

[42] C. Donadille, R. Valle, P. Dervin, R. Penelle, Development of texture and microstructure during cold-rolling and annealing of F.C.C. alloys: Example of an austenitic stainless steel, Acta Metallurgica. 37 (1989) 1547-1571. doi:10.1016/0001-6160(89)90123-5.

[43] A. Mozaffari, H. Danesh Manesh, K. Janghorban, Evaluation of mechanical properties and structure of multilayered $\mathrm{Al} / \mathrm{Ni}$ composites produced by accumulative roll bonding (ARB) process, Journal of Alloys and Compounds. 489 (2010) 103-109.

doi:10.1016/j.jallcom.2009.09.022.

[44] H.-W. Kim, S.-B. Kang, N. Tsuji, Y. Minamino, Elongation increase in ultra-fine grained Al-Fe-Si alloy sheets, Acta Materialia. 53 (2005) 1737-1749. doi:10.1016/j.actamat.2004.12.022.

[45] L.P. Kubin, A. Mortensen, Geometrically necessary dislocations and strain-gradient plasticity: a few critical issues, Scripta Materialia. 48 (2003) 119-125. doi:10.1016/S13596462(02)00335-4. 
[46] A.J. Wilkinson, A new method for determining small misorientations from electron back scatter diffraction patterns, Scripta Materialia. 44 (2001) 2379-2385. doi:10.1016/S13596462(01)00943-5.

[47] A.J. Wilkinson, D. Randman, Determination of elastic strain fields and geometrically necessary dislocation distributions near nanoindents using electron back scatter diffraction, Philosophical Magazine. 90 (2010) 1159-1177. doi:10.1080/14786430903304145.

[48] S.L. Lohr, Sampling: design and analysis, 2nd ed, Brooks/Cole, Boston, Mass, 2010.

[49] D. Hull, D.J. Bacon, Introduction to dislocations, 5. ed, Elsevier/Butterworth-Heinemann, Amsterdam, 2011.

[50] J.P. Hirth, J. Lothe, Theory of dislocations, Wiley, 1982.

[51] J.D. Eshelby, F.C. Frank, F.R.N. Nabarro, XLI. The equilibrium of linear arrays of dislocations., The London, Edinburgh, and Dublin Philosophical Magazine and Journal of Science. 42 (1951) 351-364. doi:10.1080/14786445108561060.

[52] Y.T. Zhu, X.Z. Liao, X.L. Wu, Deformation twinning in nanocrystalline materials, Progress in Materials Science. 57 (2012) 1-62. doi:10.1016/j.pmatsci.2011.05.001.

[53] W.Z. Han, A. Misra, N.A. Mara, T.C. Germann, J.K. Baldwin, T. Shimada, S.N. Luo, Role of interfaces in shock-induced plasticity in $\mathrm{Cu} / \mathrm{Nb}$ nanolaminates, Philosophical Magazine. 91 (2011) 4172-4185. doi:10.1080/14786435.2011.603706.

[54] X. Feaugas, On the origin of the tensile flow stress in the stainless steel AISI $316 \mathrm{~L}$ at 300 K: back stress and effective stress, Acta Materialia. 47 (1999) 3617-3632. doi:10.1016/S13596454(99)00222-0.

[55] A. Misra, J.P. Hirth, R.G. Hoagland, Length-scale-dependent deformation mechanisms in incoherent metallic multilayered composites, Acta Materialia. 53 (2005) 4817-4824. doi:10.1016/j.actamat.2005.06.025.

[56] N.A. Mara, D. Bhattacharyya, R.G. Hoagland, A. Misra, Tensile behavior of 40nm $\mathrm{Cu} / \mathrm{Nb}$ nanoscale multilayers, Scripta Materialia. 58 (2008) 874-877.

doi:10.1016/j.scriptamat.2008.01.005.

[57] T.G. Nieh, T.W. Barbee, J. Wadsworth, Tensile properties of a free-standing Cu/Zr nanolaminate (or compositionally-modulated thin film), Scripta Materialia. 41 (1999) 929-935. doi:10.1016/S1359-6462(99)00240-7.

[58] H.S. Shahabi, M. Eizadjou, H.D. Manesh, Evolution of mechanical properties in SPD processed $\mathrm{Cu} / \mathrm{Nb}$ nano-layered composites, Materials Science and Engineering: A. 527 (2010) 5790-5795. doi:10.1016/j.msea.2010.05.087.

[59] N.A. Mara, I.J. Beyerlein, Interface-dominant multilayers fabricated by severe plastic deformation: Stability under extreme conditions, Current Opinion in Solid State and Materials Science. 19 (2015) 265-276. doi:10.1016/j.cossms.2015.04.002.

[60] J.S. Carpenter, R.J. McCabe, J.R. Mayeur, N.A. Mara, I.J. Beyerlein, Interface-Driven Plasticity: The Presence of an Interface Affected Zone in Metallic Lamellar Composites, Advanced Engineering Materials. 17 (2015) 109-114. doi:10.1002/adem.201400210. 


\section{Figures/Table Captions}

Figure 1. Optical microscopy of (a) N2, (b) N3, (c) N5 samples, respectively. It clearly shows the inter-layer contrast and the interface spacing. Ion channeling contrast microscopy images of microstructures at copper/bronze interfaces in (d) N2, (e) N3 and (f) N5 samples.

Figure 2. (a) TEM micrograph of a copper/bronze interface in the ARB N5 sample shows wellbonded interface and big grain size difference across it. (b) Retained rolling microstructure in the bronze layer. The arrow indicates the rolling direction. (c) Grain size distribution in the copper layers based on ICCM images. (d) Transverse grain size distribution in bronze layers based on TEM micrographs.

Figure 3. (a) Micro-hardness (with a 15g load) in both the copper and bronze layers in N2, N3, N5 samples after annealing. (b) $\{100\},\{110\},\{111\}$ Pole figures in both copper and bronze layers in N3 sample after annealing, showing a strong cube texture and a brass-type texture with slight deviation, respectively. N2 and N5 have similar texture characteristics.

Figure 4. (a) Tensile curves of N2, N3 and N5 samples show simultaneous increase of strength and elongation with increasing number of layers. (b) Summary of tensile results. Error bars represents standard deviation from at least 3 data sets.

Figure 5. Transverse-direction (TD) inverse pole figure mapping of the regions around interfaces in (a-c) N2, (d-f) N3 and (g-i) N5 samples under different tensile strain levels: 0\%, 3\% and maximum uniform elongation.

Figure 6. GND density mapping based on local misorientation results in (a-c) N2, (d-f) N3 and (g-i) N5 samples under different tensile strains: 0\%, 3\% and maximum uniform elongation.

Figure 7. Global GND density distribution on corresponding mapping results in Figure 6. The mean value of GND density and the standard deviation are labeled in each histogram.

Figure 8. Averaged GND density in copper layer versus the equivalent distance from the interfaces at different strain levels of (a) N2 sample, (b) N3 sample, (c) N5 sample. Dashed green lines represent pile-up model fitting results.

Figure 9. Micro-hardness in layer interior at uniformly elongated sample region after tension. Dashed lines represent the base level before tensile tests.

Figure 10. (a) A TEM micrograph of copper/bronze interface in the N5 sample after tensile test. (b) The high-resolution image of the marked square in (a). Inset is a diffraction pattern, which shows the zone axis of copper side is $\langle 110\rangle$. The symmetric diffraction spots reveal the 
annealing twin in the copper grain, which is also marked in the image. A deformation twin in bronze side is highlighted as well. Nucleation site for the deformation twin is marked by an arrow.

Figure 11. (a) Unloading-reloading tensile curves of N2, N3, N5 samples. (b) The calculated back stress at corresponding strain levels.

Table 1. Chemical compositions and general material properties of raw materials $[35,36]$

\begin{tabular}{|c|c|c|c|c|c|c|}
\hline \multicolumn{7}{|c|}{ Chemical Compositions (wt.\%) } \\
\hline & $\mathrm{Cu}$ & $\mathrm{Pb}$ & $\mathrm{Fe}$ & $\mathrm{O}$ & $\mathrm{Zn}$ & Others \\
\hline Copper & $\geq 99.90$ & ------ & ------ & 0.04 & ------ & $\leq 0.06$ \\
\hline Bronze & $89.0 \sim 91.0$ & $\leq 0.05$ & $\leq 0.05$ & ------ & 10.0 & ------ \\
\hline \multicolumn{7}{|c|}{ Material Parameters } \\
\hline & $a(\AA)$ & $\gamma_{\mathrm{SF}}\left(\mathrm{mJ} / \mathrm{m}^{2}\right)$ & & & $v$ & $G(\mathrm{GPa})$ \\
\hline Copper & 3.61 & 45 & & & 0.324 & 44 \\
\hline Bronze & 3.64 & 35 & & & 0.307 & 44 \\
\hline
\end{tabular}




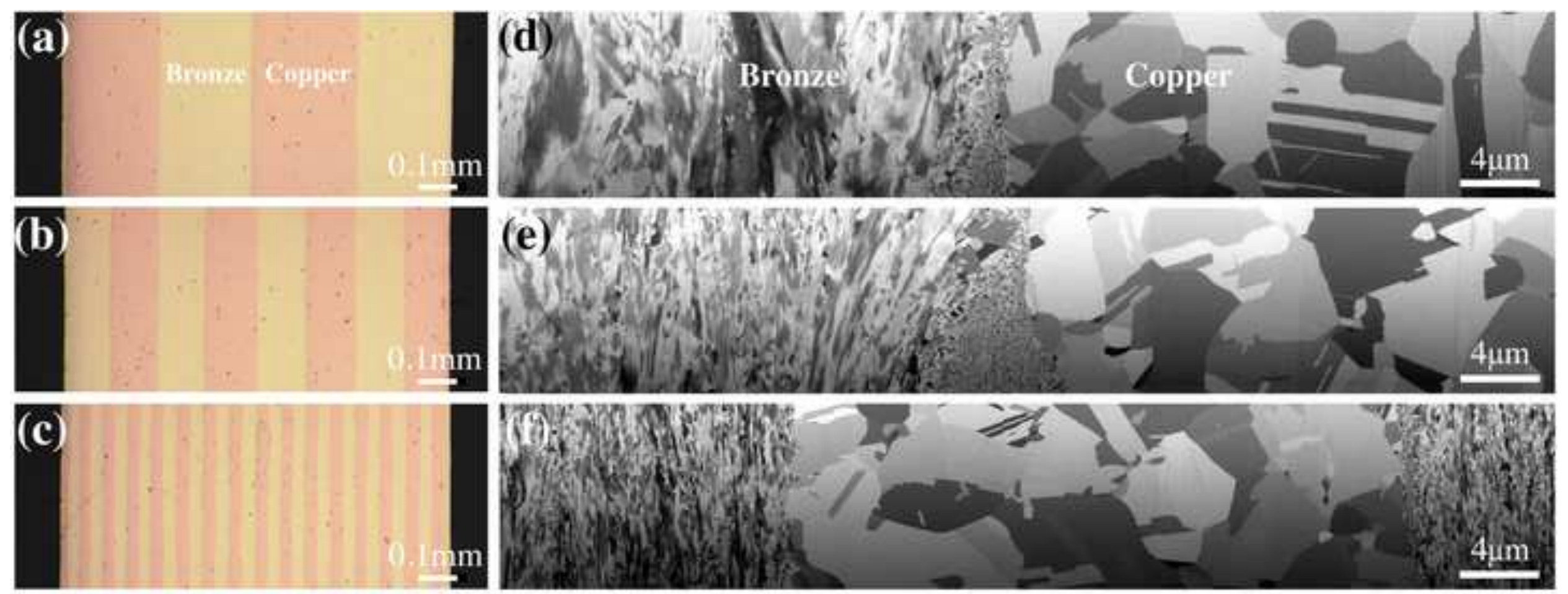

Figure 1. Optical microscopy of (a) N2, (b) N3, (c) N5 samples, respectively. It clearly shows the inter-layer contrast and the interface spacing. lon channeling contrast microscopy images of microstructures at copper/bronze interfaces in (d) N2, (e) N3 and (f) N5 samples. 
(a)

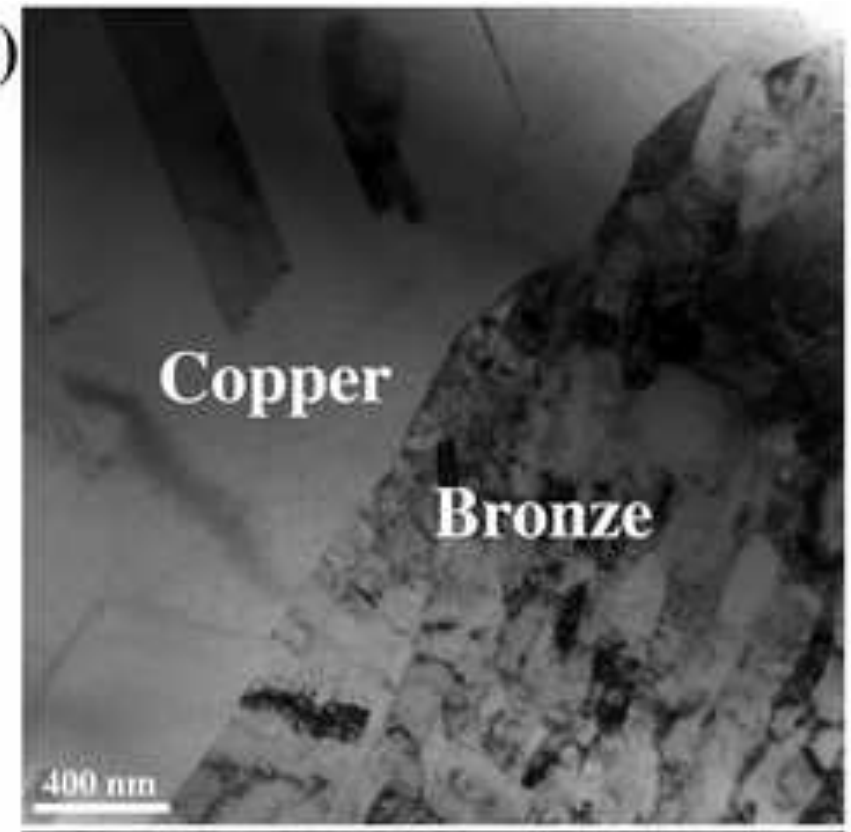

(b)

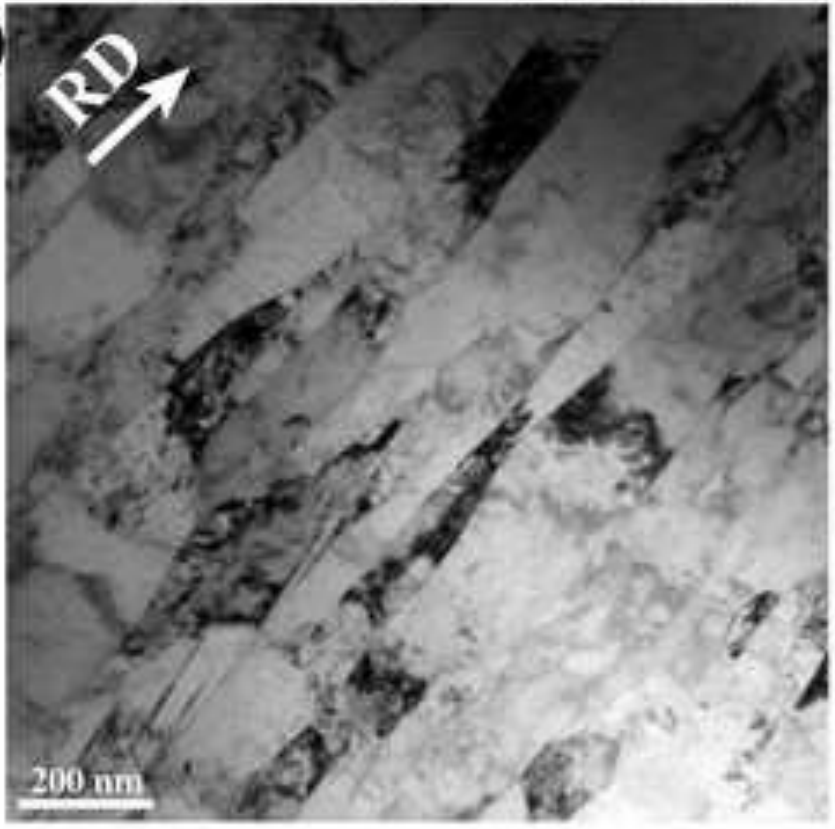

(c)

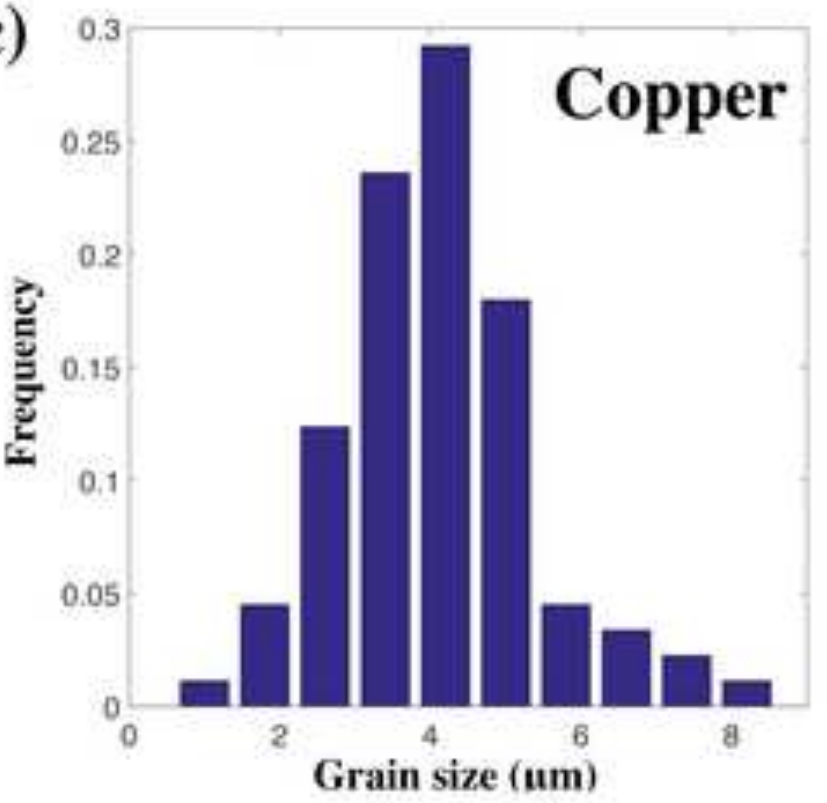

(d)

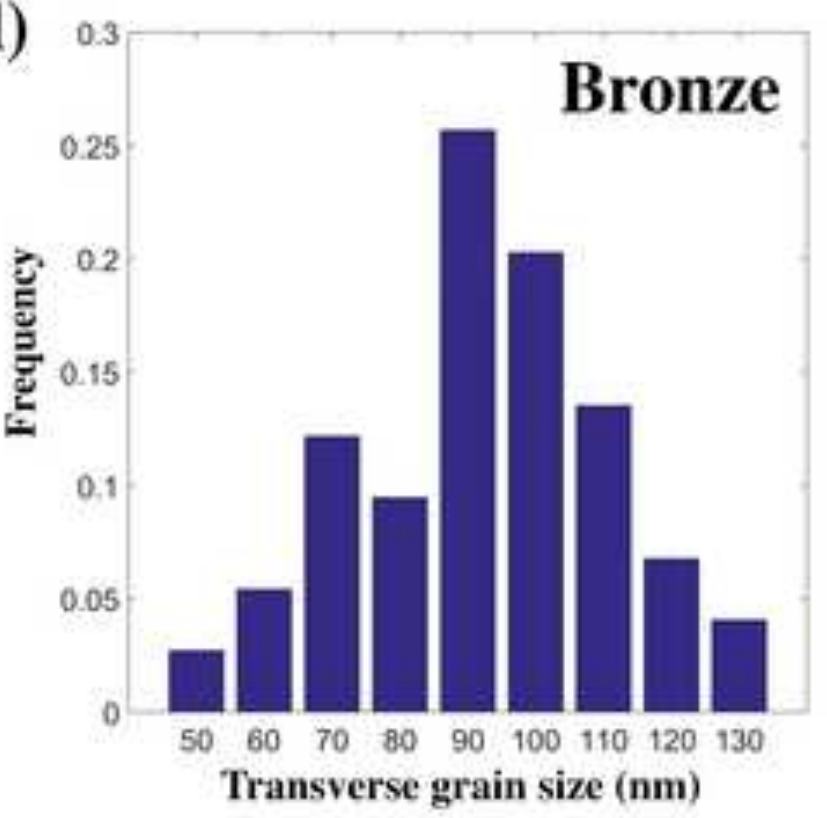

Figure 2. (a) TEM micrograph of a copper/bronze interface in the ARB N5 sample shows well-bonded interface and big grain size difference across it. (b) Retained rolling microstructure in the bronze layer. The arrow indicates the rolling direction. (c) Grain size distribution in the copper layers based on ICCM images. (d) Transverse grain size distribution in bronze layers based on TEM micrographs. 
(a)

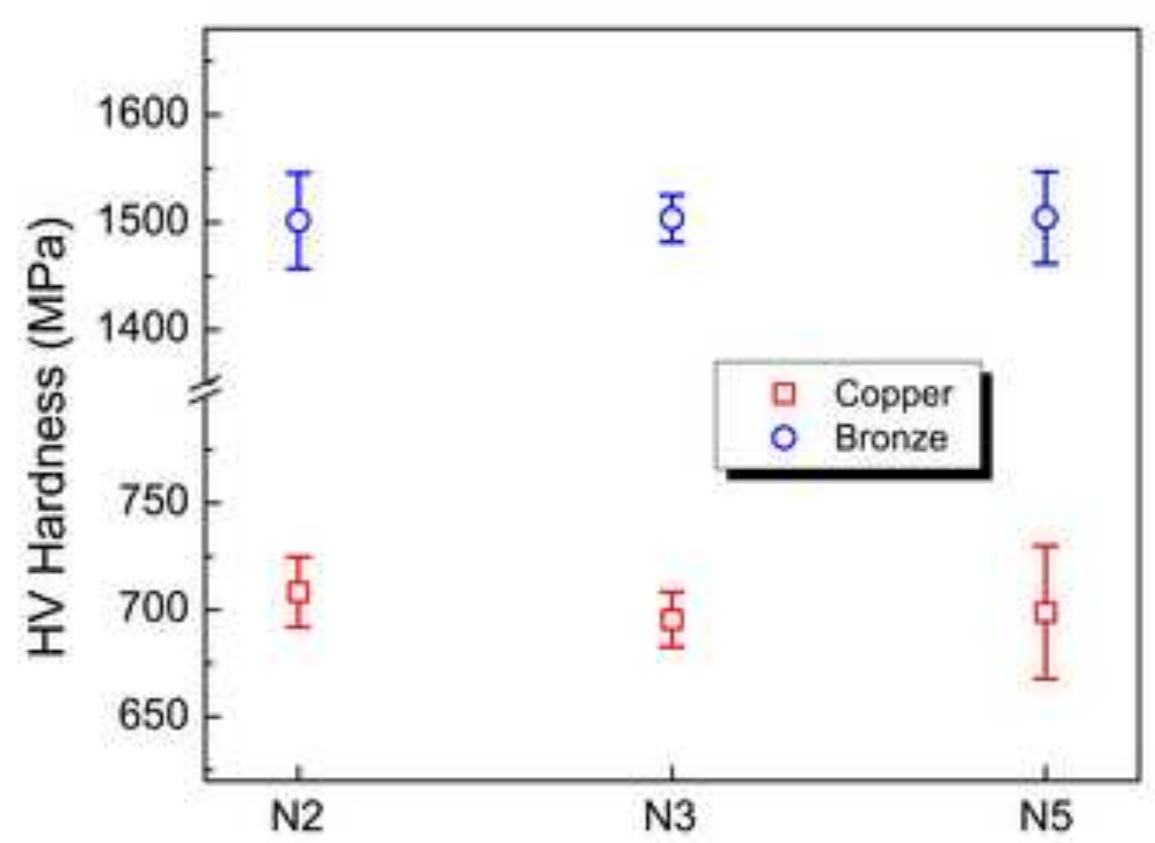

(b)
Copper
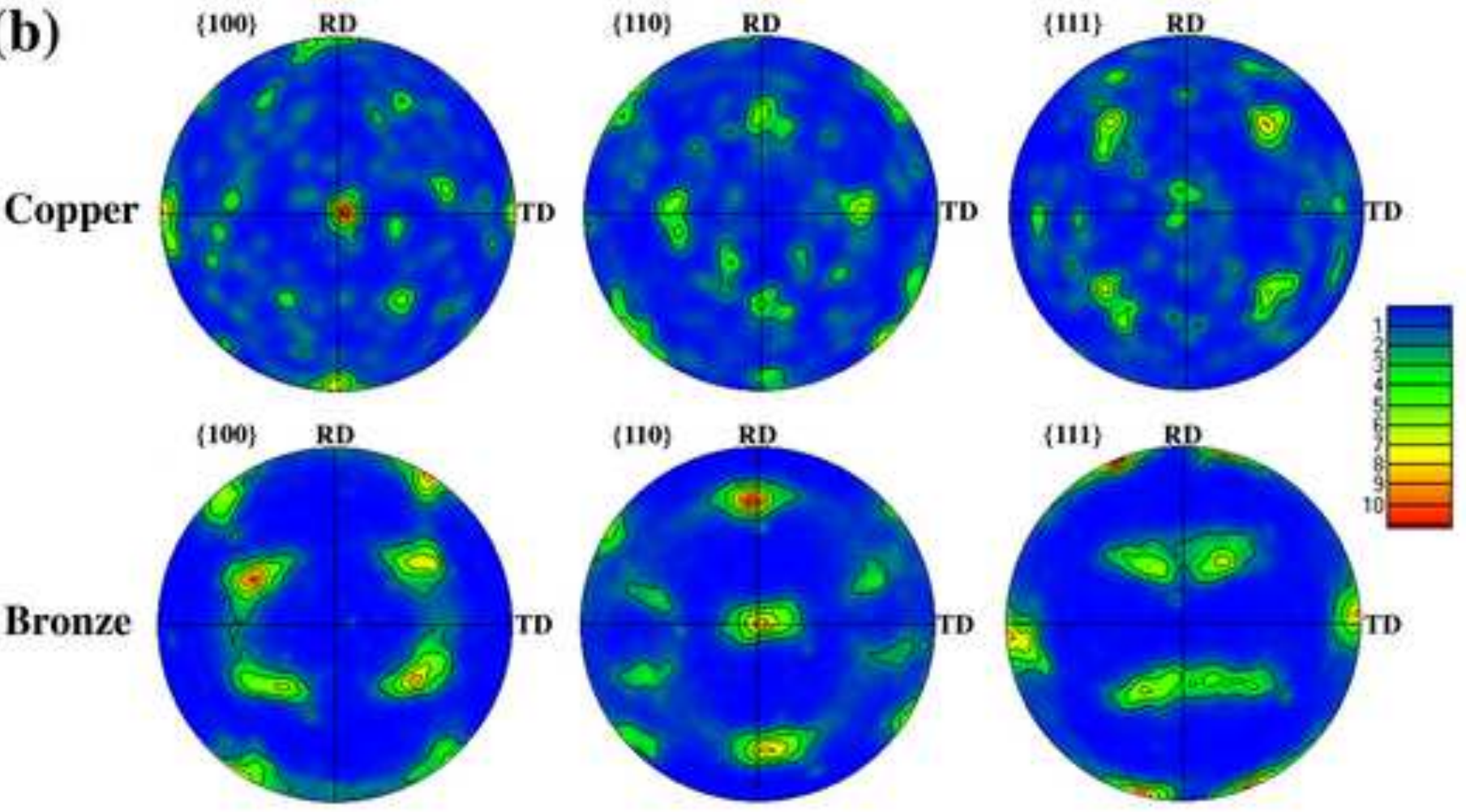

Figure 3. (a) Micro-hardness (with a 15g load) in both the copper and bronze layers in N2, N3, N5 samples after annealing. (b) $\{100\},\{110\},\{111\}$ Pole figures in both copper and bronze layers in N3 sample after annealing, showing a strong cube texture and a brass-type texture with slight deviation, respectively, N2 and N5 have similar texture characteristics. 
(a)

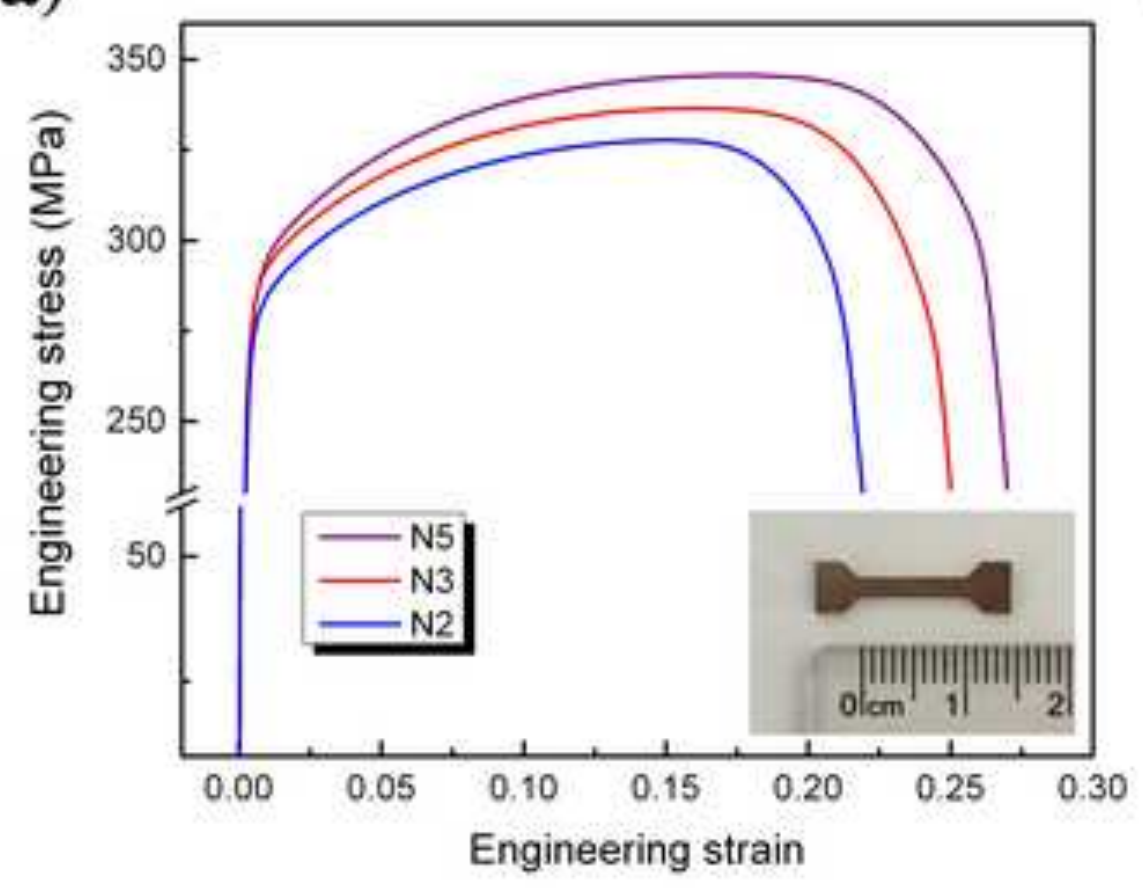

(b)

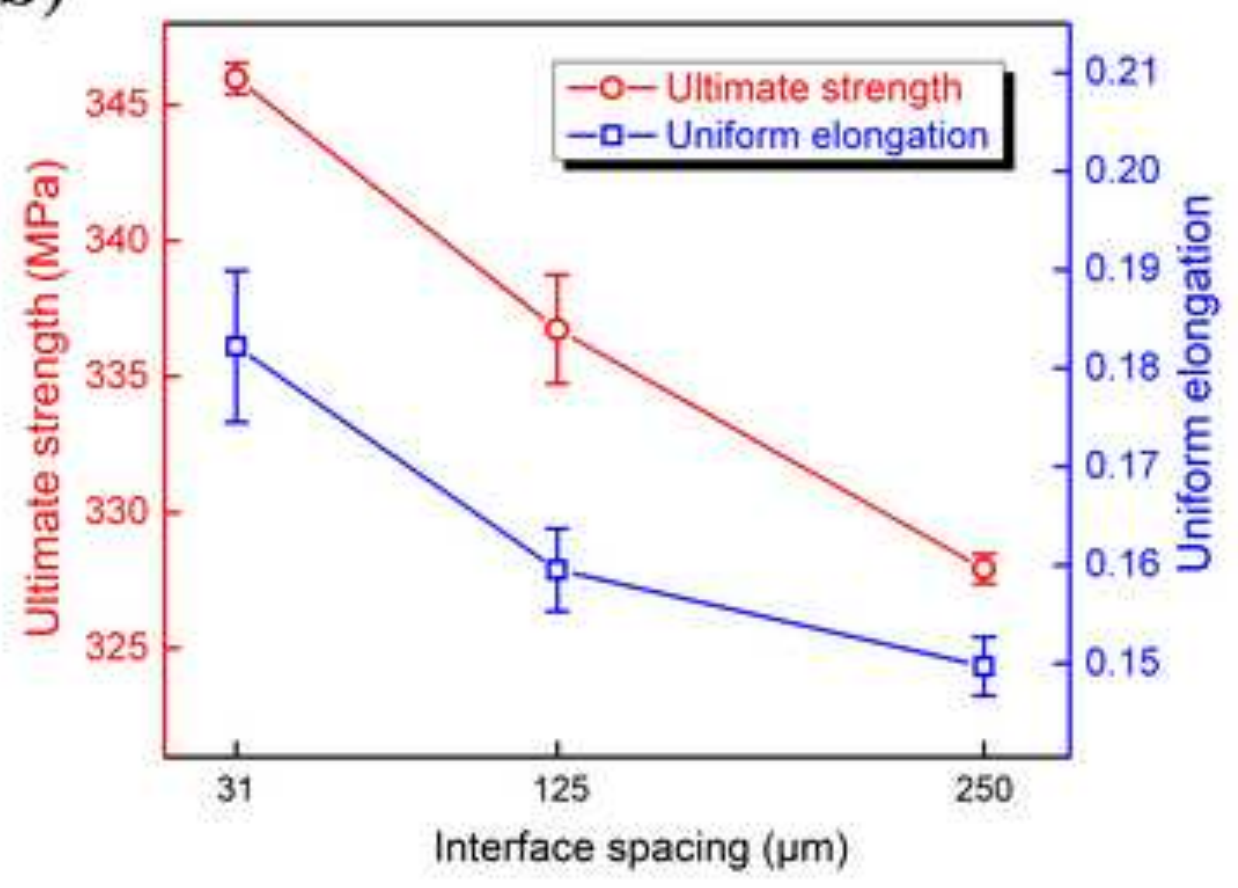

Figure 4. (a) Tensile curves of N2, N3 and N5 samples show simultaneous increase of strength and elongation with increasing number of layers. (b) Summary of tensile results. Error bars represents standard deviation from at least 3 data sets. 


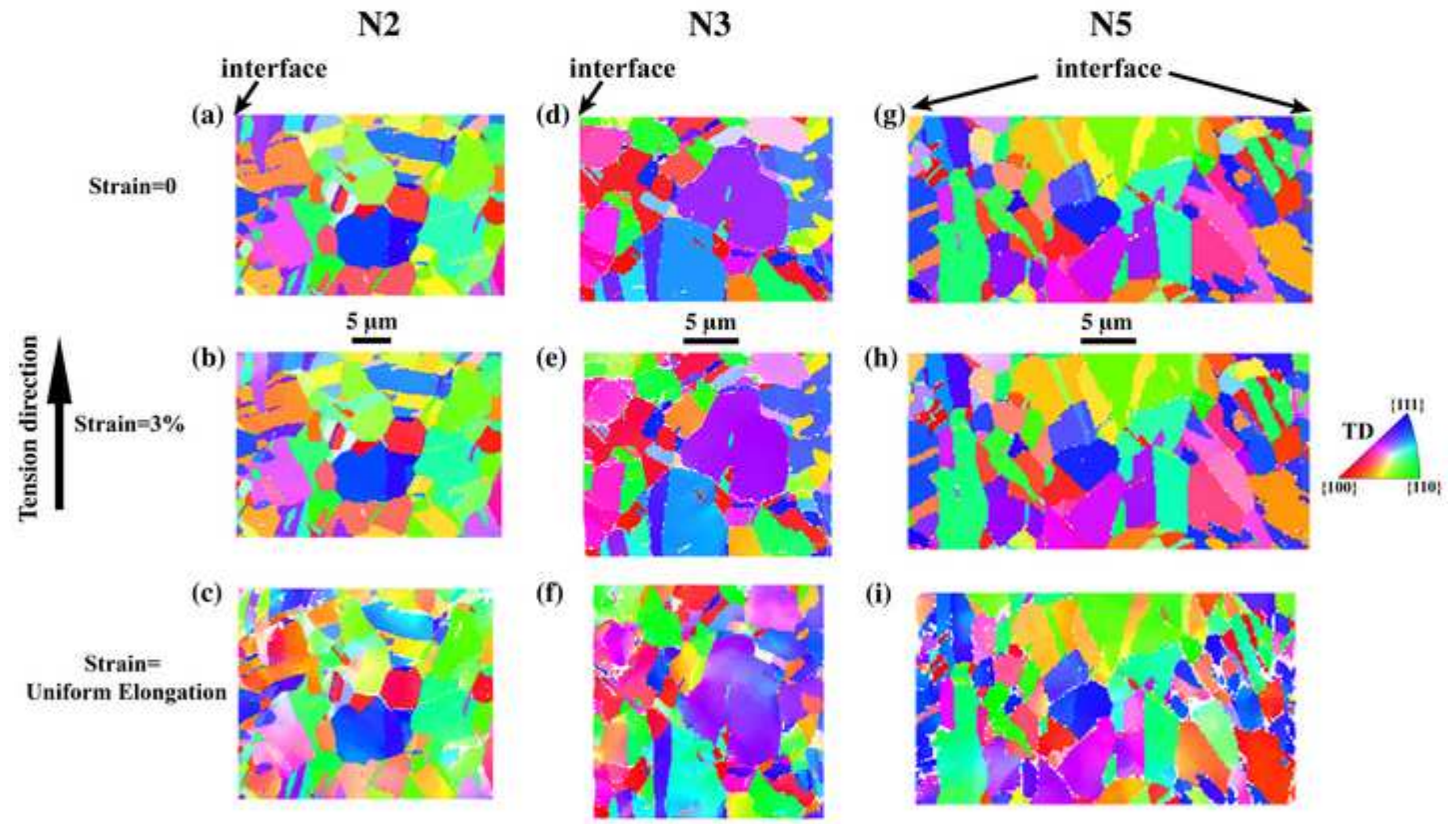

Figure 5. Transverse-direction (TD) inverse pole figure mapping of the regions around interfaces in (a-c) N2, (d-f) $\mathrm{N} 3$ and $(\mathrm{g}-\mathrm{i}) \mathrm{N} 5$ samples under different tensile strain levels: $0 \%, 3 \%$ and maximum uniform elongation. 


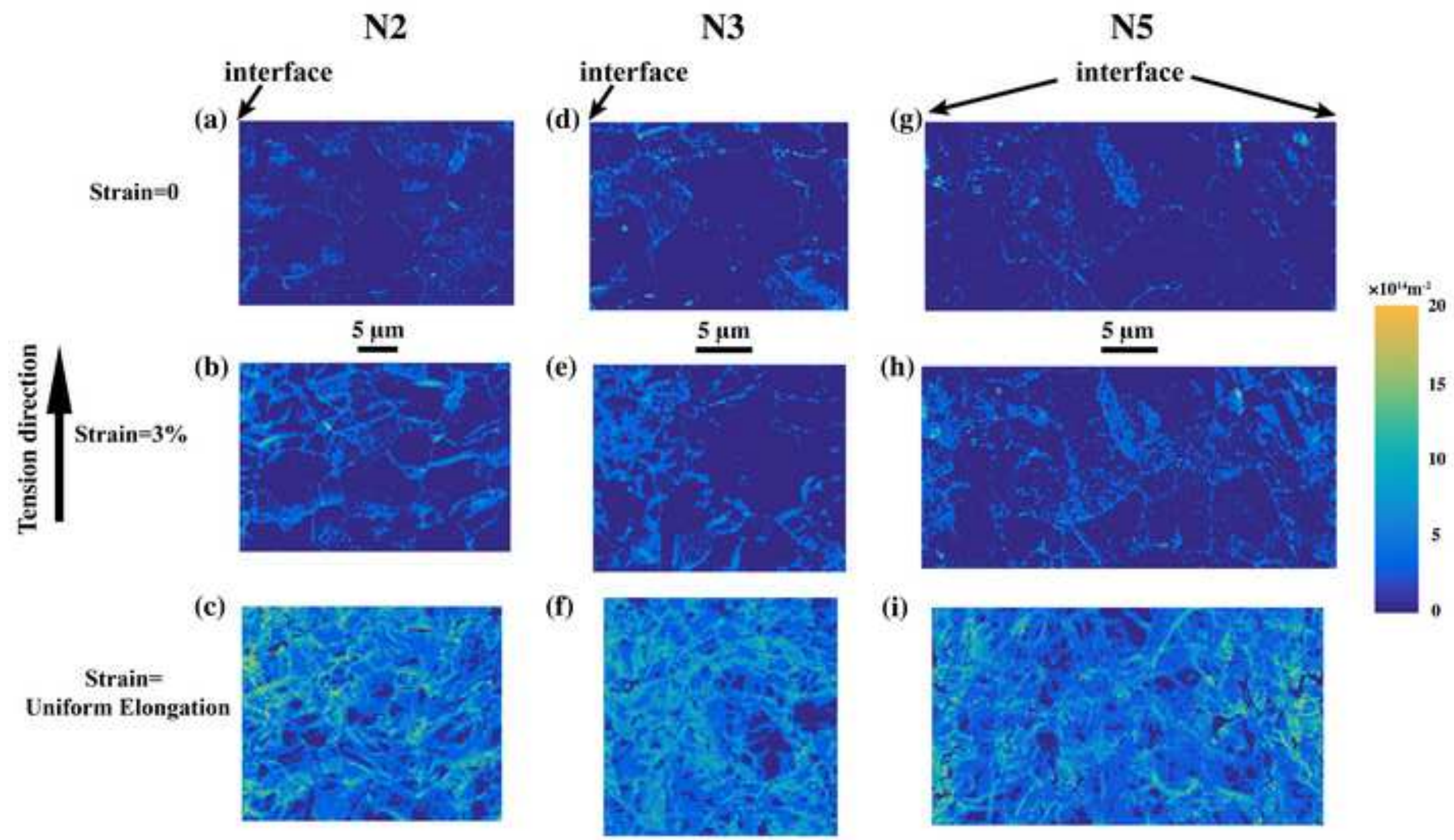

Figure 6. GND density mapping based on local misorientation results in (a-c) N2, (d-f) N3 and (g-i) N5 samples under different tensile strains: $0 \%, 3 \%$ and maximum uniform elongation. 

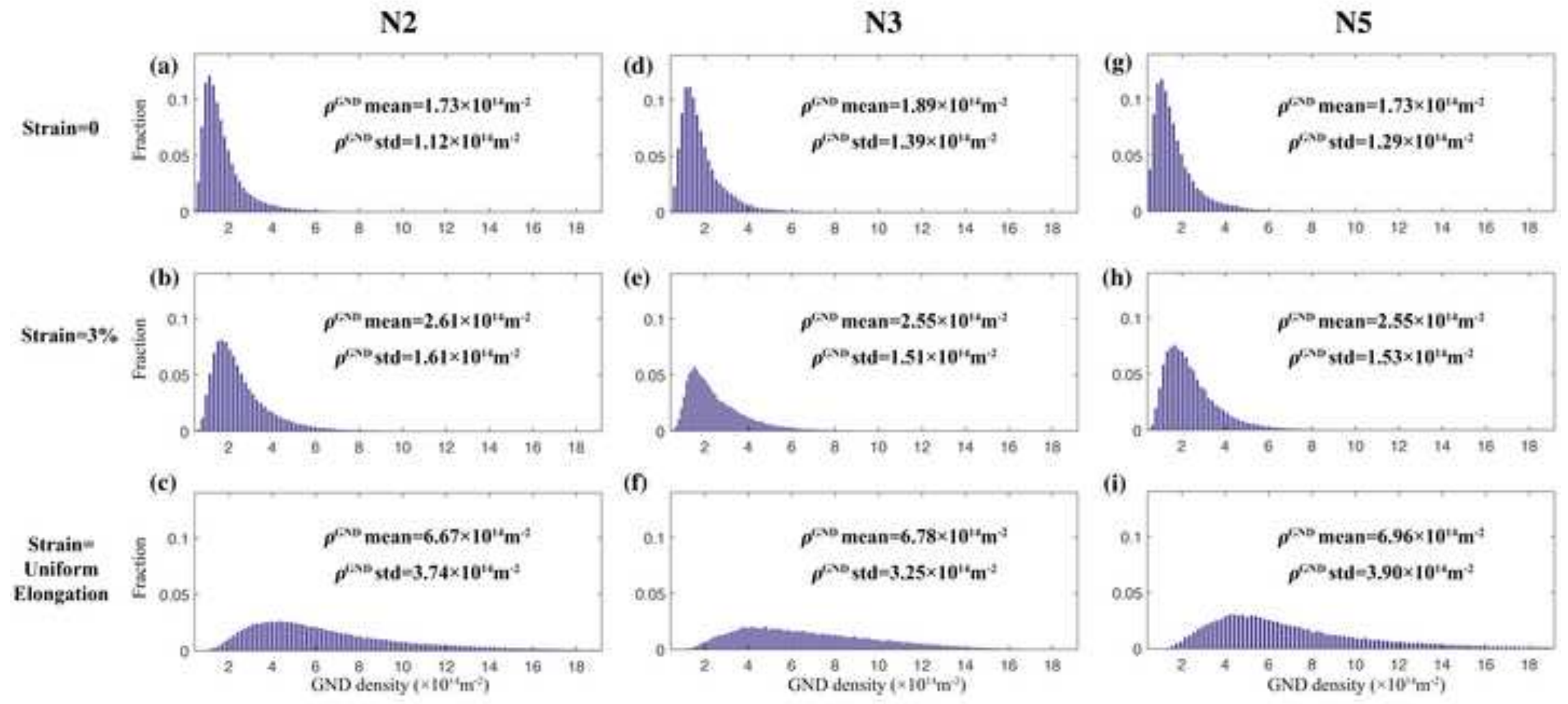

Figure 7. Global GND density distribution on corresponding mapping results in Figure 6. The mean value of GND density and the standard deviation are labeled in each histogram. 

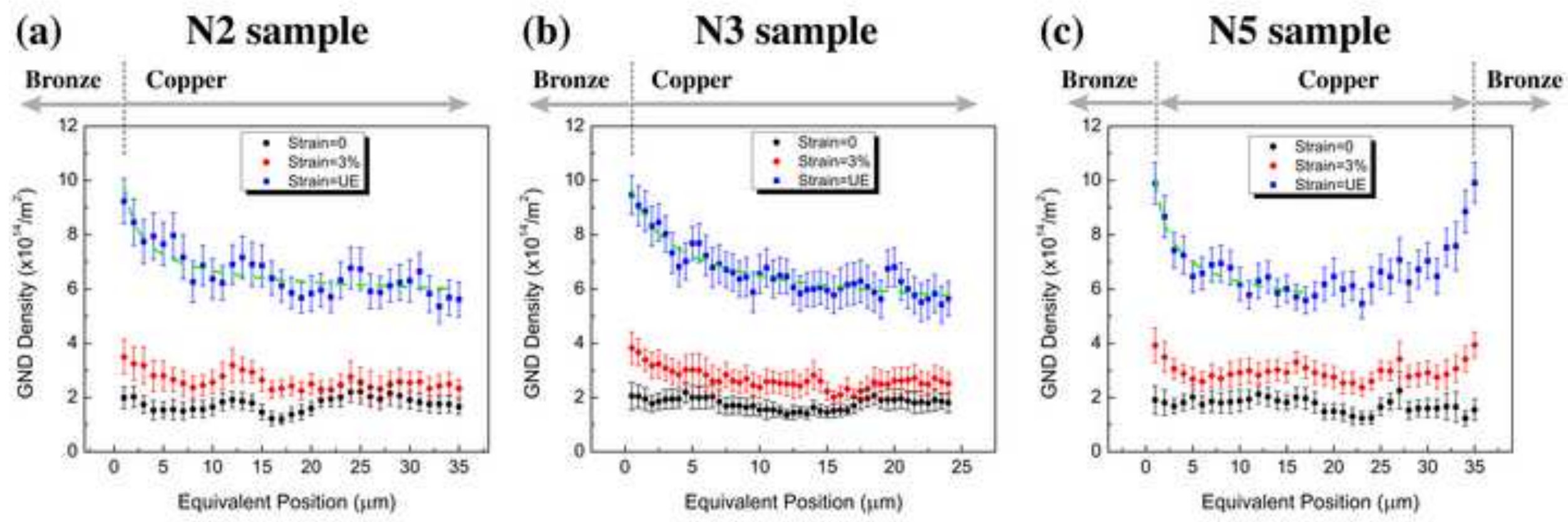

Figure 8. Averaged GND density in copper layer versus the equivalent distance from the interfaces at different strain levels of (a) N2 sample, (b) N3 sample, (c) N5 sample, Dashed green lines represent pile-up model fitting results. 


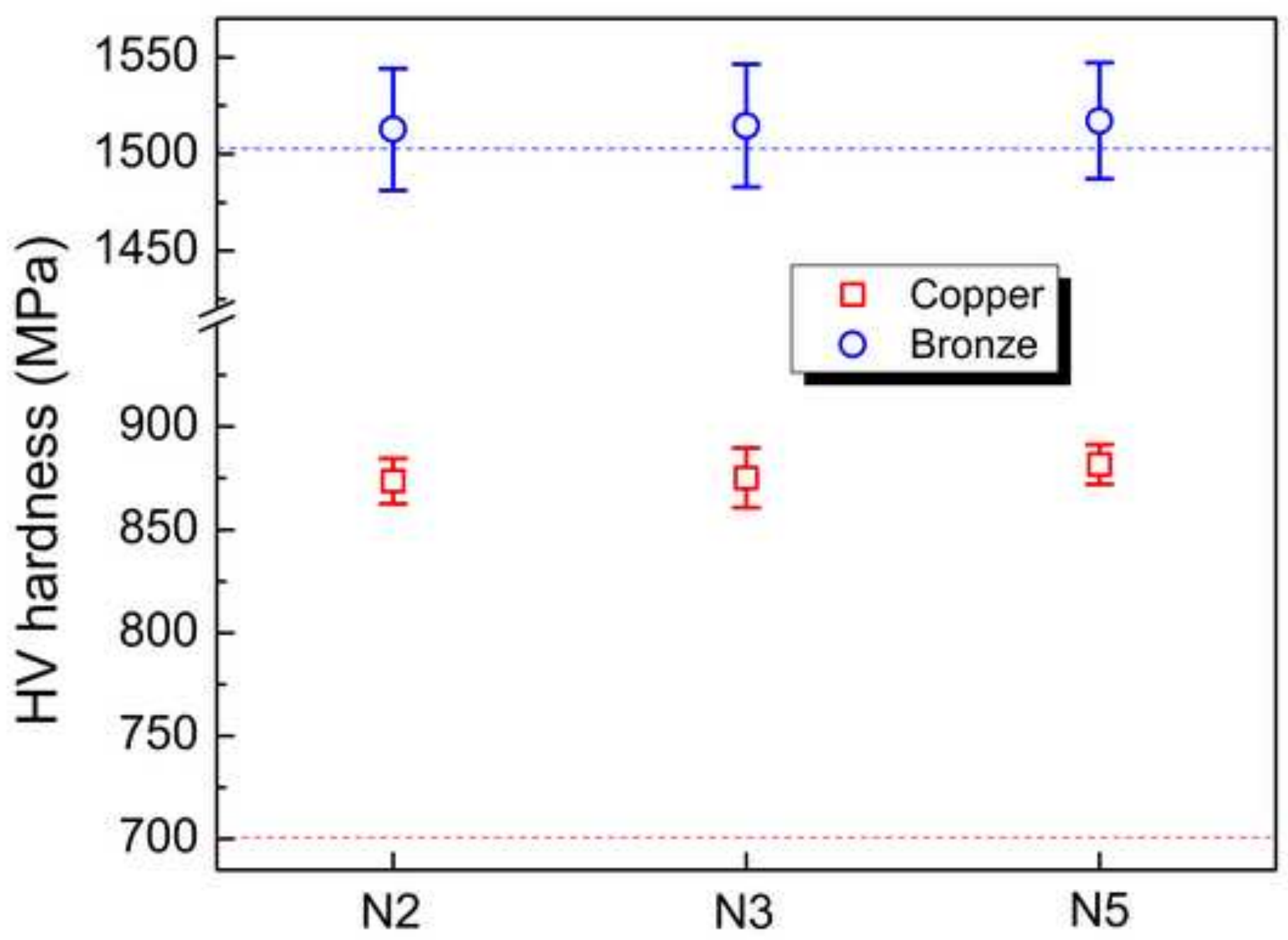

Figure 9. Micro-hardness in layer interior at uniformly elongated sample region after tension. Dashed lines represent the base level prior to tensile tests. 

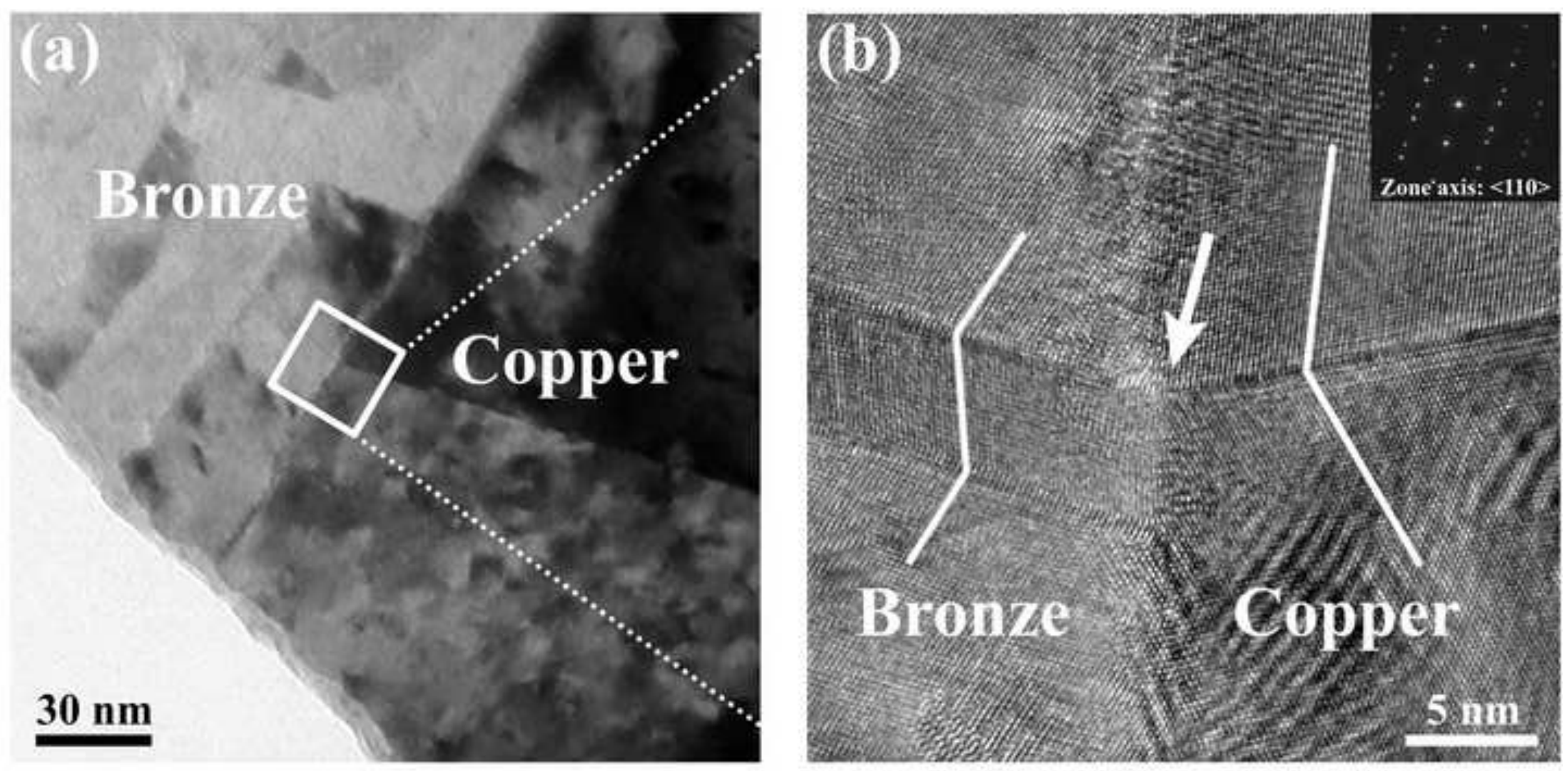

Figure 10. (a) A TEM micrograph of copper/bronze interface in the N5 sample after tensile test. (b) The high-resolution image of the marked square in (a). Inset is a diffraction pattern, which shows the zone axis of copper side is $\langle 110\rangle$. The symmetric diffraction spots reveal the annealing twin in the copper grain, which is also marked in the image. A deformation twin in bronze side is highlighted as well. Nucleation site for the deformation twin is marked by an arrow. 

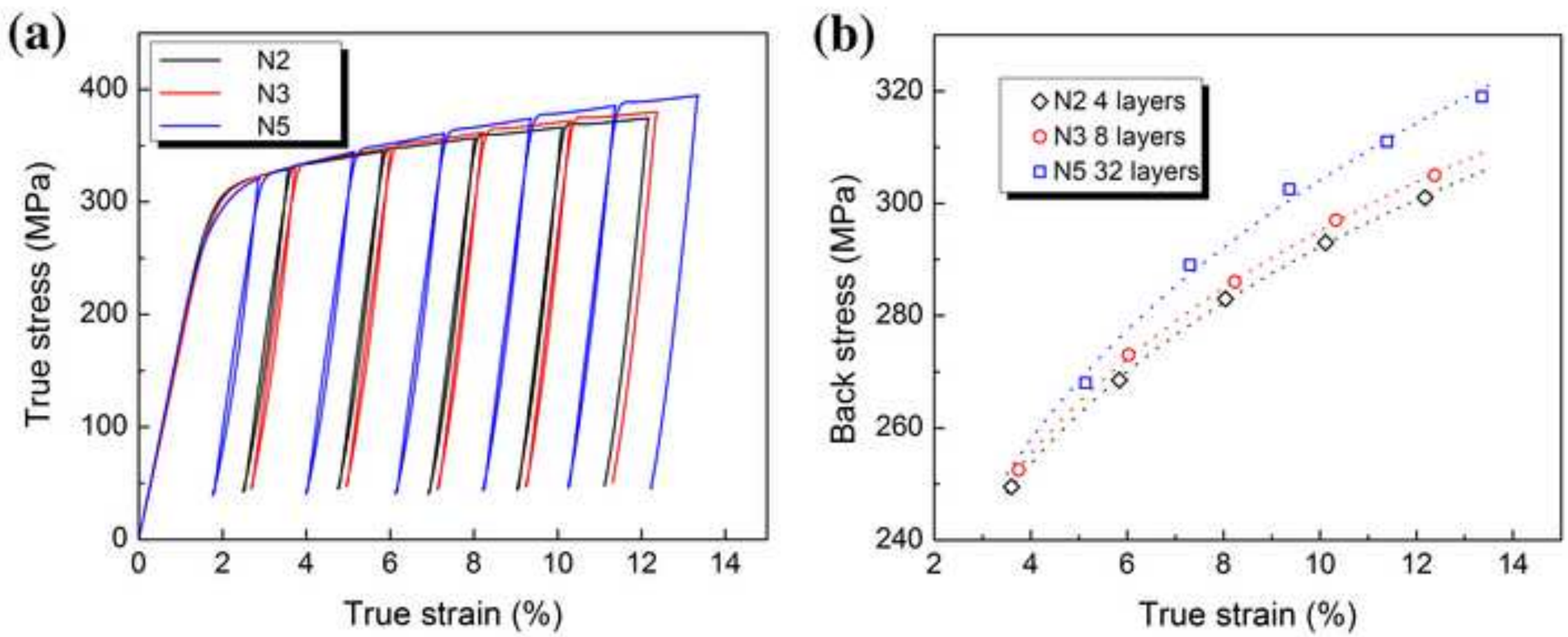

Figure 11. (a) Unloading-reloading tensile curves of N2, N3, N5 samples. (b) The calculated back stress at corresponding strain levels. 

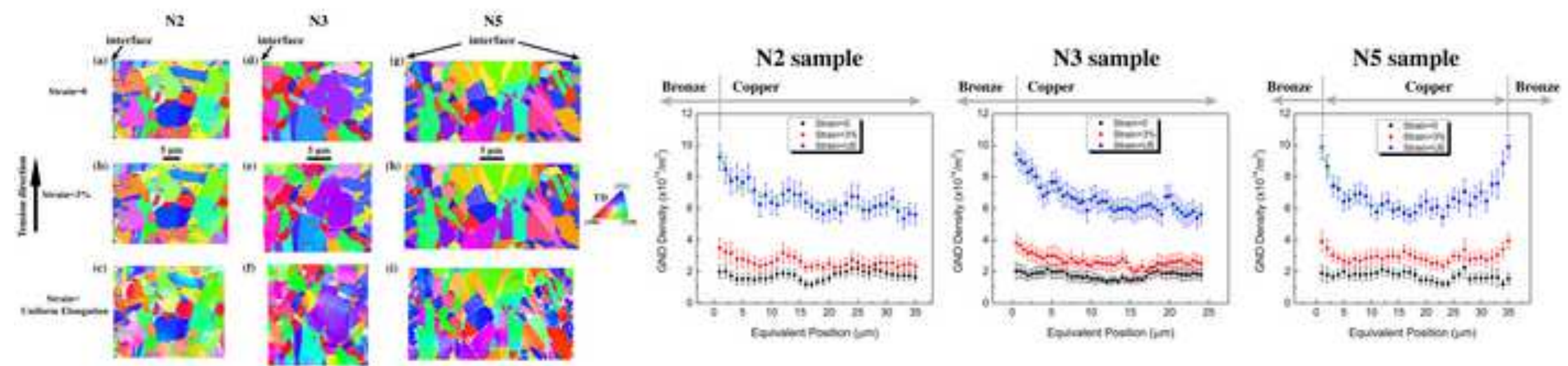